other branches of psychiatry, in default of these services, and not by nature of their appointment.

T PILkINGTON

Aycliffe Hospital
Darlington, Co Durham DL5 6QA

\section{Sewage treatment}

SIR,-The aim of conventional sewage treatment in this country is more limited than was suggested in your leading article (26 January, p 206) "No sewage in the streets." It is to reduce suspended solids and biochemical oxygen demand, although a concomitant improvement in the chemical and microbiological quality of the effluent can be expected. Some chemicals will go through the plant virtually unchanged and may find their way into water supplies. For this reason dual water supplies incorporating a small highly purified supply for drinking are desirable.

Incidentally, the Aberdeen typhoid outbreak occurred because of contamination when the Argentinian factory used untreated river water for cooling cans of meat after a break down in the chlorination plant.

JoHN E SCUTT

Department of Civil and Municipa

University College London
London WC1E 6BT

\section{Dietary fibre, sodium, and}

blood pressure

SIR,-The paper by Angela Wright and others (15 December, $p$ 1541) and the subsequent correspondence (19 January, p 181) emphasise the important roles of low sodium high potassium, and high fibre intakes in the treatment of hypertension. During the past 30 years an increasing number of epidemiologica studies on primitive populations have found that blood pressure did not rise with age and essential hypertension did not occur if adul sodium intakes averaged less than $64 \mathrm{mmo}$ $(\mathrm{mEq}) /$ day. ${ }^{1}$ Diets of these primitive group were characterised by low fat intake, $10-25 \%$ energy; high unrefined starch intake, 50-70\% energy; high dietary fibre intake, $30-50 \mathrm{~g} /$ day; and $\mathrm{a} \mathrm{K}^{+}: \mathrm{Na}^{+}$ratio greater than unity.

A diet similar in composition has been employed in the treatment of 218 patients with confirmed hypertension on medication in a residential centre in California. One hundred and eighty-six $(85 \%)$ left the centre free of medication and normotensive at the end of 30 days' treatment. ${ }^{2}$

A regimen comprising English foods has also been used in the treatment of essential hypertension at the Royal Berkshire Hospital, Reading, from March 1978 until August 1979, when the observations shortly to be published terminated. ${ }^{3}$ Outpatients with essential hypertension, all on drug therapy, were selected for a dietary regimen containing sodium $40-50 \mathrm{mmol} /$ day, potassium 80-90 $\mathrm{mmol}(\mathrm{mEq}) /$ day, energy 6.5-7.5 MJ $(1528-1793 \mathrm{kcal}) /$ day derived, in terms of energy percentages, from unrefined starch $50-60 \mathrm{~g}$, sugar

Diastolic blood pressure during dietary treatment

\begin{tabular}{|c|c|c|c|c|}
\hline & \multicolumn{3}{|c|}{ Mean diastolic pressure $(=\mathrm{SD}) \mathrm{mm} \mathrm{Hg}$} & \multirow[b]{2}{*}{9 months } \\
\hline & At entry* & 3 months & $\overline{6 \text { months }}$ & \\
\hline $\begin{array}{l}\text { No of patients } \\
\text { Supine } \\
\text { Standing }\end{array}$ & $\begin{array}{c}32 \\
98 \cdot 3( \pm 8 \cdot 2) \\
104 \cdot 7(+8 \cdot 7)\end{array}$ & $\begin{array}{l}32 \\
86 \cdot 1(9 \cdot 0) \\
90 \cdot 6(9 \cdot 0)\end{array}$ & $\begin{array}{l}23 \\
83 \cdot 5( \pm 8 \cdot 3) \\
92 \cdot 0(: 8 \cdot 2)\end{array}$ & 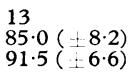 \\
\hline
\end{tabular}

${ }^{*}$ Mean of all recording during preceding 6-12 months, while receiving antihypertensive drugs.
5-10 g, fat $15 \mathrm{~g}$, protein $10-13 \mathrm{~g}$, dietary fibre $30-35$ g/day. At the end of three months' dietary therapy it was hoped to persuade patients to resume temporarily their former diet but none could be persuaded to do so.

Thirty-two patients were treated with the dietary regimen for three to nine months. As the table shows, the mean diastolic pressures fell considerably. Twelve patients ceased antihypertensive therapy completely as supine blood pressure on several occasions was below $90 \mathrm{~mm} \mathrm{Hg}$. Seven patients reduced drug therapy considerably but supine diastolic pressure was seldom below $90 \mathrm{~mm}$ $\mathrm{Hg}$. Six other patients reduced drug therapy but supine diastolic pressure had not fallen; seven patients failed to respond. Four patients gained weight on this regimen, with a similar hypotensive response to the 28 patients who lost weight. Weight changes usually stabilised without any change in the blood pressure response, or lack of response to the diet.

It is therefore hoped that further research with improved facilities, on patients suffering from mild hypertension will determine the dietary factors which influence this multifactorial disease. It is not easy to assess the effect of a complex group of substances such as dietary fibre.

St Bartholomew's Hospital,

P M DoDsoN

${ }^{1}$ Tobian L. In: Conesti G, Klimt CR, eds. Hypertension: determinants, complications and interve Mannerber D. Chest Heart Stroke f 1979;3:62-5.

3 Dodson P, Humphreys D. In: Trowell H, Burkitt D, eds. Western diseases: their emergence and prevention. London: Edward Arnold (in press).

\section{Lumbar puncture}

SIR,-The recent article by Dr J M A Cowan and his colleagues (26 January, p 224) on the use of desmopressin (DDAVP) in the pre vention of headache after lumbar puncture is of considerable interest. Perhaps it is appropriate to point out that DDAVP is a poten stimulant of a systemic release of the fibrinolytic proenzyme, plasminogen activator, in man. Localised release of plasminogen activator might therefore give rise to enhanced clot lysis and an exacerbation of bleeding. Experience in the use of this compound in patients with haemophilia A suggests this potential hazard is unlikely to materialise, bu I believe that it should be specifically included in any further studies, particularly in patients with suspected intracranial haemorrhage. A the same time encouragement should be given to the company manufacturing DDAVP to explore the possibility of producing another vasopressin analogue with antidiuretic activity without the side effect of releasing plasminogen activator.

Headquarters Unit,

Edinburgh EH17 7QT

SIR,-In the otherwise useful article on lumbar puncture (2 February, $p$ 297) by Drs C Clough and J M S Pearce, it is a great pity that the most important point of all in the technique - that the lumbar spines should be in a straight line when the patient is in the lateral position-is omitted. A large folded towel or a pillow must be placed beneath the waist and the doctor should check by palpation that the spines are straight before he scrubs up. The neck should not be flexed; it does not affect the lumbar spine at all, and is cruel when there is a stiff neck as in meningitis or subarachnoid haemorrhage.

J R GibBS

Haywards Heath, Sussex RH17 7NF

SIR,-I was disappointed to read that Drs C Clough and J M S Pearce still recommend Queckenstedt's test when performing a lumbar puncture (2 February, p 297). It is a useless ritual which has become part of our neurological heritage, but is of no value in any of their indications for lumbar puncture. What does concern me is that it is potentially dangerous. Queckenstedt's test increases intracranial pressure, and because lumbar punctures are still carried out indiscriminately -a sort of conditioned reflex to any neurological problem-it may precipitate coning in patients whose symptoms and signs have been misinterpreted. Queckenstedt's test should be abandoned, and regarded as an evolutionary vestige of the days before myelography.

By the way, how often does examination of the cerebrospinal fluid affect the management of patients with suspected multiple sclerosis? Another conditioned reflex ?

DAVID THRUSH

Neurological Department,

Plymouth General Hospital,

SIR,-As a regular user of spinal anaesthesia I was interested to read the suggestions of $\mathrm{Dr}$ J M A Cowan and others (26 January, p 224) for reducing problems in those patients unfortunate enough to require lumbar puncture for diagnostic and therapeutic reasons. The reported incidence of headaches following lumbar puncture varies enormously, depending on the size of the needle used and how expertly it is wielded; on the age, sex, and condition of the patient; and on which of the many possible preventive measures has been instituted.

An incidence of only $0.5 \%$ was found in a study by Brocker, ${ }^{1}$ who, having collected on average $13 \mathrm{ml}$ of cerebrospinal fluid (CSF) via an 18 gauge needle, instructed each patient to lie prone for three hours before resuming ambulant activity. This result compared very favourably with the $37 \%$ incidence in his smaller "control" group of patients who lay supine for the three hours. Such a significant difference is difficult to explain, but Brocker suggested that assumption of the prone position staggers the punctures in the dura and arachnoid; decreases the potential epidural space, thus minimising any effect that a subatmospheric pressure in this space may have on CSF loss; and releases the tension on the dural and arachnoid tears-these would reduce the loss of CSF and provide optimal conditions for rapid healing. Whatever the explanation the results are convincing, and this simple measure has the added advantages of being non-invasive as well as requiring less restriction on the patient's activity than many other regimens, such as 24 hours' strint supine bed rest. The discomfort that some may experience by lying on their abdomen for short period of time is a small price to pay for 